\title{
Las relaciones entre la filosofía y la teoría literaria
}

Recibido: septiembre 22 de 2017 | Aceptado: mayo 7 de 2018

DOI: 10.17230/co-herencia.15.29.9

\author{
Germán Garrido Miñambres* \\ gegarrid@pdi.ucm.es
}

\begin{abstract}
Resumen El artículo aborda el potencial que ofrece la filosofía para la renovación de los presupuestos críticos manejados por la teoría literaria indagando en dos aspectos fundamentales. Por un lado, cuestiona que la identificación de la filosofía con la literatura auspiciada por la deconstrucción excluya otras formas de relación entre sus respectivos ámbitos competenciales. Por el otro, propone una forma de hacer productiva la filosofía para la teoría que pasa no tanto por la ampliación de los referentes textuales ya consagrados por la poética como por la plena exploración de sus contextos originales. En lugar de promover la especulación en torno a nuevas referencias filosóficas, se trata de devolver esas referencias a sus entornos textuales de procedencia para obtener nuevas implicaciones de antiguas formulaciones teóricas.
\end{abstract}

\section{Palabras clave:}

Teoría literaria, filosofía, poética, textos programáticos, romanticismo.

\section{On the relationships between philosophy and literary theory}

\begin{abstract}
This paper addresses the potential of philosophy to renew the critical assumptions of literary theory by examining two key aspects. On the one hand, it challenges the belief that the identification of philosophy with literature, promoted by deconstruction, implies the exclusion of other forms of relationship between their respective fields of expertise. On the other hand, it proposes a way to make philosophy productive for theory which involves not so much the expansion of the textual referents already established by Poetics but rather the full exploration of its original contexts. Instead of promoting speculation around new philosophical references, what is at issue here is to restitute these references to their original textual environments in order to derive new implications from ancient theoretical formulations.
\end{abstract}

\section{Keywords:}

Literary theory, philosophy, poetics, programmatic texts, romanticism.
Profesor de la Facultad de Filología de la Universidad Complutense Madrid, España. ORCID ID: 0000-0002-9935-3257 
La aproximación entre filosofía y teoría literaria que proponen las siguientes páginas toma como punto de partida la poética, entendida como el lugar donde se trata la incidencia que tiene el contexto discursivo de una determinada época en su correspondiente concepción literaria. A través de las distintas variantes que componen su corpus programático -los manifiestos, prólogos, artículos, disertaciones y tratados que expresan un parecer sobre el sentido último de la actividad literaria-, la poética da cuenta también de las deudas que esa concepción literaria mantiene con su tradición filosófica. La teoría literaria moderna nos ha demostrado con creces que los préstamos entre dos ámbitos del conocimiento no se restringen a esas marcas textuales explícitas. La vía que aquí se plantea para superar esa limitación no pasa sin embargo tanto por explorar vínculos relacionales ajenos a los ya transitados por la poética, como por devolver estos al lugar que ocupaban en sus fuentes filosóficas de origen. Lejos de perseguir con ello solo la fidedigna restauración del sentido que denotaban los conceptos filosóficos antes de ser adoptados por la poética, este procedimiento permite reinterpretar la incidencia de esos conceptos a la luz que sobre ellos proyectan sus entornos textuales de procedencia.

Antes de desarrollar esta premisa con ejemplos concretos (como la disputa entre filosofía y literatura en Platón o el principio kantiano de la conformidad a fin sin fin), mostraremos cómo la deliberada confusión entre los ámbitos competenciales filosófico y literario promovida por la deconstrucción no excluye la existencia de otras modalidades relacionales entre la filosofía y la literatura, y menos aún entre la filosofía y la teoría literaria. Repasaremos algunas de esas modalidades señaladas por la crítica durante los últimos tiempos para terminar centrándonos en la poética, principal predecesora del entramado relacional que une a la filosofía con la teoría literaria, en la creencia de que puede contribuir a renovar los fundamentos metodológicos de esta última.

\section{Más allá del paradigma competencial}

Durante las últimas décadas el debate sobre las relaciones entre filosofía y literatura ha estado monopolizado por la cuestión acerca de sus límites e interferencias. La crítica radical a la tradición logo- 
céntrica planteada por la deconstrucción igualaba el criterio de verdad manejado por la filosofía al de la literatura, cuestionando a la postre cualquier distinción entre sus respectivos ámbitos discursivos. Si Derrida equiparaba la historia de la metafísica a la de las metáforas y metonimias que le han servido de centro (1987, p. 385), son conocidos los esfuerzos de Paul de Man (1998) por mostrar la condición retórica subyacente a las posiciones clásicas de la filosofía moderna.

La reducción del espectro relacional entre la literatura y la filosofía a lo que podríamos llamar su disputa competencial se ha mantenido desde los años ochenta como una constante de este campo interdisciplinar. La pervivencia de dicho enfoque se advierte todavía en títulos de referencia como el A Companion to the Philosophy of Literature de Hargberg \& Jost (2010), ${ }_{1}^{1}$ cuyo primer apartado "Relations between Philosophy and Literature" sigue centrando sus contribuciones en las concomitancias y divergencias entre ambas variantes discursivas. Así, por ejemplo, Arthur C. Danto cuestiona por un lado que la literatura se base exclusivamente en relaciones referenciales de verticalidad con los textos de la tradición y la filosofía en relaciones verticales que la vinculan con la realidad. Al mismo tiempo retoma sin embargo la antigua distinción aristotélica entre literatura e historia concluyendo que el universal al que se refiere la literatura es aquel que el receptor del texto identifica como propio entre una multiplicidad de mundos posibles. La filosofía por su parte aspira como la literatura a tener validez universal, pero a diferencia de ella exige ser necesaria en todos y cada uno de los mundos posibles (Danto, 2010, p. 63). ${ }^{2}$

Aunque los logros alcanzados por este planteamiento crítico resultan incuestionables, ${ }^{3}$ su éxito invita a hacer al menos dos consideraciones. En primer lugar, lejos de responder a un descu-

1 En lo que respecta a la crítica autóctona da muestra de esta problemática el libro de Manuel Asensi (1995), único manual aparecido en nuestro país sobre el tema.

2 El modelo competencial no se restringiría en rigor a la deconstrucción, abarcando también el pragmatismo de un Rorty, e incluso el enfoque de la teoría crítica, que se opone a estos presupuestos pero al precio de mantener su atención en la disputa acerca de los límites disciplinares. Comprende por tanto las tres corrientes que según Carlos Thiebaut (1995) se entrecruzan en la disputa entre filosofía y literatura.

3 Logros que no deben ocultar los peligros de su instrumentalización, como recuerda José Luis Pardo (2002, pp. 13-15). 
brimiento reciente, la disputa competencial entre filosofía y literatura es tan antigua como la convivencia de ambas disciplinas. Como señala Roland Duhammel (1995, pp. 117 y ss.), los comentarios de Schelling sobre el valor filosófico del arte, la preeminencia dada al pensamiento intuitivo sobre el racional desde la fenomenología o las reflexiones estéticas planteadas por la teoría crítica de Adorno constituyen, no ya los preliminares, sino los capítulos centrales de una vieja controversia que se remonta hasta Aristóteles. El desmantelamiento hermenéutico operado por la deconstrucción equivaldría por tanto solo a una variante más del gesto interrogativo que ha mantenido ocupada a una larga tradición. Aun asumiendo que los presupuestos incorporados por la impronta deconstructiva introducen elementos innovadores en esta confrontación, su trasfondo crítico remite a un extenso legado dialéctico que relativiza su vocación transgresiva.

Pero al margen de su dudosa novedad, es evidente que el planteamiento competitivo no agota las posibles modalidades relacionales entre filosofía y literatura como podría invitar a pensar la presencia casi exclusiva que ha tenido en el debate especializado desde los años ochenta. Por un lado, la literatura ha proporcionado toda suerte de materiales referenciales a la filosofía, ya sea en forma de figuras ilustrativas (la Antígona de Hegel, el Quijote de Ortega, el Robinson de Deleuze...), de autores paradigmáticos (el Dante de Schelling, el Hölderlin de Heidegger, el Proust de Sartre), o de tropos iluminadores (las referencias homéricas de Platón, el lenguaje poético de Nietzsche). Más allá de estas elementales formas de préstamo se sitúan los casos en que la literatura se convierte en interlocutora directa de la controversia filosófica. Así, Stanley Cavell muestra cómo la respuesta a la problemática del escepticismo inaugurada por Kant, encuentra en la literatura romántica una vía de continuidad alternativa a la filosófica. La réplica del romanticismo al escepticismo se manifiesta como un intento de salvar el vínculo entre el yo y el mundo, entre la consciencia y las cosas (Cavell, 2002, p. 109). Por su parte, Bernard Williams encuentra en el sentido que los textos literarios de la antigüedad conceden a conceptos morales como el de la vergüenza una superación del principio de autonomía propio de la moral kantiana (2011, pp. 127-166). En la misma dirección se 
orientan las investigaciones de Martha Nussbaum (2005, pp. 235 274; 2010, pp. 241-246) sobre la contribución literaria de autores como Henry James a la filosofía moral. ${ }^{4}$

Igualmente manifiestas resultan las transferencias que se producen en sentido contrario desde la filosofía a la literatura. Ya se trate de la influencia ejercida por un determinado pensador sobre un escritor o un entorno cultural específicos (el Freud de los surrealistas, el Bergson de Proust o el Schopenhauer de Baroja), de la impronta dejada por algún concepto reflexivo (el amor neoplatónico en la lírica petrarquista, el Zeitgeist hegeliano en los realistas del XIX o el rizoma de Deleuze entre los posmodernos) o del modo específico en que la literatura presta voz a temas filosóficos (la libertad del juicio estético kantiana en Schiller, la experiencia de Bergson en Proust o la ocultación heideggeriana del ser en cierta lírica del pasado siglo), la tradición literaria demuestra alimentarse de la filosofía como lo hace de otras muchas variantes discursivas. Y también aquí constatamos la existencia de apropiaciones que desbordan las modalidades de trasvase más elementales, como sucede cuando el texto literario asume como fin implícito la réplica cuando no la impugnación de un debate filosófico. Es el modo en que procede Maurice Blanchot (1992, p. 37) cuando parte del "espacio literario" para indagar sobre la experiencia de la muerte o Philip Kitcher (2013, p. 17) cuando entiende que el texto literario amplía como representación visual el horizonte del filosófico.

Todas estas variantes relacionales son igual de importantes y reivindicables, todas ellas proporcionan a la literatura un entorno dialógico análogo al que conforman otros campos de conocimiento. Si la consagración del paradigma competitivo no conlleva su pérdida de vigencia, menos aún puede hacerlo con la modalidad discursiva que cifra su interés precisamente en la recepción de ideas filosóficas. ${ }^{5}$ La teoría de la literatura ocupa un papel mediador central en el tránsito informativo entre literatura y filosofía. Desde el momento en

4 En el ámbito de la investigación autóctona merece ser destacado el estudio de Rocío Orsi sobre Sófocles (2007, pp. 29-31).

5 Podría añadirse como una variante intermedia la influencia de la filosofía en la transformación de los paradigmas científicos que guían el estudio filológico, como sucede cuando la germanística rompe definitivamente con el positivismo de la mano de Wilhelm Dilthey (Sauerland, 1993, p. 256). 
que asumen una concepción general del lenguaje y el arte, sus distintas escuelas remiten directa o indirectamente al horizonte conceptual en el que se originan, estableciendo así un diálogo permanente con las fuentes filosóficas. La filosofía no solo está presente en la teoría literaria cuando esta la invoca como autoridad o señala como referente directo, lo hace también a través de presupuestos implícitos en el contexto intelectual correspondiente sin necesidad de caer en la indistinción entre filosofía y literatura propia del paradigma competencial. Así, la estética de la recepción se beneficia de la hermenéutica de Gadamer y Dilthey, pero a través de ella también de la fenomenología y la dialéctica. Más aún, el diálogo entre texto y receptor asumido por la escuela de Constanza puede verse prefigurado en los procedimientos interpretativos de la exégesis bíblica o la mayéutica socrática. De este sustrato conceptual se beneficia sin duda la teoría literaria aunque su alcance haya sido frecuentemente ignorado por el paradigma competencial. Más allá de cuanto concierne al conflicto de atribuciones entre filosofía y literatura se trataría pues de replantear no solo el alcance retrospectivo de sus intercambios, trasvases y mutuas aportaciones, sino también, íntimamente ligado a este, el prospectivo de su potencial crítico e interpretativo.

Lo cierto es que durante los últimos tiempos se aprecia una creciente tendencia a recuperar el potencial crítico que la teoría literaria encuentra en la tradición filosófica, desde que Peter V. Zima (1995) se atreviera a situar la totalidad de la teoría literaria moderna a la luz de las estéticas kantiana y hegeliana, hasta que Peter Lamarque (2009) propusiera más recientemente una filosofía de la literatura a medio paso entre la indistinción de filosofía y literatura que a su juicio persigue la teoría literaria y el reduccionismo filológico de los estudios históricos. En el primer caso, Zima (1995, pp. 6-7) entiende que las distintas posiciones adoptadas por la teoría literaria durante el pasado siglo se dejan distribuir en dos concepciones estéticas fundamentales: la que mantiene suspendido el juicio artístico-literario en una indeterminación conceptual priorizando la dimensión expresiva sobre la significativa, y la que con Hegel vincula ese mismo juicio a la progresiva manifestación del espíritu racional en la naturaleza, anteponiendo la dimensión conceptual a la expresiva. Zima concede a las estéticas de Kant y Hegel un valor explicativo meramente hipotético e instrumental sobre los postulados de la 
teoría literaria, sin pretender en ningún momento que las primeras agoten las implicaciones contenidas en las propuestas de las segundas. La tradición estética proporcionaría solo el marco unitario de coordenadas elementales sobre el cual proyectar los diversos pronunciamientos de la teoría literaria. Así, el estructuralismo de Goldmann se afilia a la vertiente hegeliana y el formalismo de Sklovskij o Tynjanov a la de Kant (Zima, 1995, pp. 90-99), mientras la teoría crítica de Adorno se ubica a medio camino entre ambas (1995, pp. 156-168). Por su parte, Lamarque (2009, pp. 9-12) pone de manifiesto cómo el callejón sin salida al que parece abocarse la teoría de la literatura desde los años noventa obliga a buscar un impulso renovador en la tradición filosófica. ${ }^{6}$ Con independencia del crédito que merezcan los fundamentos constitutivos de lo que él entiende por filosofía de la literatura, su propuesta evidencia la demanda de un ámbito relacional no supeditado al paradigma competencial.

Los distintos aspectos de esta problemática quedaban ya de manifiesto en el libro de Christopher Norris Spinoza and the origins of modern Crirical Theory (1991); Norris distinguía con claridad meridiana en su libro las influencias de Spinoza sobre la teoría literaria moderna basadas en relaciones textuales probadas de las que obedecen solo a inferencias indirectas. Lo interesante es que incluso circunscribiéndose a la primera clase de relaciones, Norris constata cómo la influencia de Spinoza da lugar a posturas contrapuestas. Así, mientras Althusser la invoca como autorizada para respaldar una interpretación marxista heterodoxa de la ideología (Norris, 1991, p. 35), Deleuze y Foucault lo hacen para fundamentar la primacía de la percepción sensitiva sobre la racional, de la percepción corporal sobre la lógica. Una misma fuente filosófica permite pues tanto respaldar la base racional de la teoría como impugnarla, sin que puedan aducirse razones incontrovertibles para priorizar una opción sobre la contraria. Pero Norris opta por ir más allá del espectro referencial inmediato señalando una analogía entre la recepción de Spinoza entre sus contemporáneos y la de Salman Rushdie y sus Versos satánicos. Lo hace convencido de que Spinoza prefigura un procedimiento hermenéutico que rechaza el dogmatismo de la

6 No es preciso convenir con Lamarque o Eagleton (2005) en que la época de la teoría literaria ha llegado a su fin, para reconocer que la filosofía podría contribuir sustancialmente a reimpulsarla. 
sujeción a un código interpretativo determinado sin renunciar, sino antes bien apoyándose, en la distinción entre los textos ficcionales y los no ficcionales y sus respectivas pretensiones de veracidad (Norris, 1991, p. 114). Contravendría así el proceder de cierta crítica deconstructiva sin supeditarse por ello a la exigencia de un sentido específico, conforme a la postura adoptada por cierta tradición teórica moderna heredera de Althusser a la que Norris se afilia. En la lectura de las Sagradas Escrituras planteada por Spinoza, así como en su forma de referirse a las problemáticas de la realidad histórica, descubre Norris un precedente teórico ejemplar, que no funciona por tanto solo como autoridad implícita o soterrado motivo inspirador, sino también como modelo valorativo. Lejos de limitarse a señalar la huella de una influencia filosófica, Norris la adopta como faro y guía de un específico método interpretativo. ${ }^{7}$ En trabajos posteriores, Norris volverá sobre las relaciones entre filosofía y teoría literaria, abundando en el potencial que estas siguen reservando a tópicos como la teoría de los mundos posibles o el alcance del lenguaje trópico (2007, pp. 134-211).

\section{De la poética a la teoría literaria}

Recapitulemos: aunque las relacionales entre filosofía y literatura consolidan su prestigio como campo de estudio a partir sobre todo de que la posmodernidad cuestionara la tajante distinción del discurso filosófico y el literario, el trasvase entre ambas disciplinas había abordado ya con anterioridad sus distintos aspectos tanto desde el punto de vista de la filosofía como de la literatura. Por un lado, la presencia de la literatura en la filosofía contempla el uso ejemplificativo de textos y autores, el empleo de imágenes y tropos extraídos del lenguaje literario o el de motivos y problemáticas frecuentadas por la tradición poética, pero también la aportación

7 Podría decirse entonces que Norris contraviene sus propios presupuestos violentando el sentido de un testimonio filosófico, el de Spinoza, para adecuarlo a los intereses de una postura teórica determinada, la que él sostiene frente a la deconstrucción. Con todo lo que esa apropiación pueda tener de cuestionable, la remisión de Norris a Spinoza descubre el terreno mayoritariamente ignorado en el estudio de las relaciones entre literatura y filosofía que desborda el cauce de las influencias textuales probadas, constituido por el repertorio de textos programáticos que alimenta una tradición poética y que proporciona un espacio privilegiado para el diálogo y la recepción del discurso filosófico. 
específica que ofrece la literatura al planteamiento de problemas filosóficos. ${ }^{8}$ Por el otro, la impronta filosófica en la literatura abarca el tratamiento literario que reciben ciertos temas filosóficos, la influencia manifiesta ejercida en un autor o entorno cultural determinado, las concepciones filosóficas que a menudo subyacen a ciertas variantes discursivas y recursos formales o la incidencia en el concepto mismo de literatura planteado por el contexto discursivo de una u otra época, esto es, la teoría literaria y su inmediata predecesora, la poética. ${ }^{9}$

La poética acusa como rasgo distintivo una particular sujeción a las pruebas textuales proporcionadas por los documentos programáticos: los manifiestos, prólogos, artículos, disquisiciones y tratados que jalonan el cauce de una determinada tradición expresando el parecer de autores, teóricos, opinadores y preceptistas sobre el sentido último de la actividad literaria. Esa sujeción se extiende también a la impronta de la filosofía en la poética, de tal forma que la concepción literaria vigente en cada contexto discursivo manifiesta su herencia filosófica a través fundamentalmente de los textos programáticos. De este modo, Castelvetro acusa la influencia del neoplatonismo en una época en que la poética se confundía aún con la retórica (Garrido Gallardo, 2014, p. 180), como Gottsched remitirá en el siglo XVIII a su maestro Wolff, y a través de él, al pensamiento de Leibniz; Grimmelshausen invoca a Aristóteles para justificar su poética de la novela en el Simplicissimus, como Cándido María Trigueros recuerda a Alexander Pope en el prólogo a El poeta filósofo (Garrido Miñambres, 2010, p. 137). Ya se trate de las disertaciones artístico-poéticas más generales o de los prólogos, declaraciones y comentarios más específicos, el corpus programático aglutina el conjunto de referencias filosóficas erigiéndose en su verdadero y último registro verificador.

Pese a las decisivas consecuencias que implica su advenimiento, el vuelco romántico no introduce alteraciones sustanciales en lo que se refiere a este punto: De l'Allemagne de Madame de Staël acusa la misma deuda con el idealismo alemán que el prefacio de Victor Hugo para su Cromwell (o las Cartas literarias a una mujer de Bécquer).

8 Bouchard (1976, p. 439) distingue en este sentido entre la literatura como objeto del discurso filosófico y como elemento del discurso filosófico.

9 Teniendo en cuenta que la poética proporciona ese sustrato a la teoría literaria junto a la retórica (Garrido Gallardo, 2001, p. 45), se conviene en que el vínculo entre poética y retórica queda definitivamente roto en la segunda mitad del siglo XVIII (Till, 2013, p. 442). 
Una de las principales novedades del Romanticismo consistió en la introducción de una nueva clase textual entre las frecuentadas por los documentos programáticos. Los escritos de Novalis y los hermanos Schlegel inauguran una forma de mediación entre filosofía y literatura donde la primera hace de la segunda su principal objeto especulativo cuando no su fundamento inspirador. Aunque no llega a establecerse como ámbito específico del conocimiento hasta entrado el siglo veinte al amparo del éxito de las ciencias sociales, la teoría literaria se remonta en realidad al giro producido por el Romanticismo en la historia de las ideas poéticas (Lacoue-Labarthe \& Nancy, 2013, pp. 33-35). ${ }^{10}$ Como consecuencia de ese acontecimiento la poética pasa de normativa a especulativa, y de asumir una finalidad descriptiva a una propositiva. La posterior evolución de la modalidad discursiva inaugurada por el Romanticismo, planteará una sustancial modificación de los objetivos tradicionalmente perseguidos por los textos programáticos sin dejar estos por ello de funcionar como canal comunicativo y certificado autorial de las relaciones entre filosofía y poética. Así continúa en efecto sucediendo tanto en el punto álgido de protagonismo alcanzado por los documentos programáticos con los manifiestos vanguardistas, como en el momento equivalente de las más intensas discusiones sostenidas dentro de la teoría literaria. A despecho de las múltiples diferencias que evidencian sus respectivas clases textuales, ambas siguen presentando claras afinidades que se manifiestan también en el modo de reflejar la influencia filosófica. Minturno acusa la impronta de Aristóteles como Schiller la de Kant o Iser la de Gadamer si nos atenemos tanto al crédito que uno y otro confían a sus fuentes, como al que en ellas deposita la ulterior tradición poética. En ambos casos, el documento textual detenta una particular facultad orientativa que le antepone de entrada a otros referentes en virtud de la evidencia probatoria que se presume en el testimonio directo.

10 La hipótesis de que la teoría literaria nace con el Romanticismo no está exenta de controversia. Si, como recuerda Culler (2002, pp. 38-39), la teoría se pregunta no tanto por la "literatura" (cuya concepción sufre en efecto un vuelco total con el romanticismo), como por la "literariedad", su origen debería fijarse en el formalismo ruso. 
Vemos así que, cuando no queda expuesta a la indiscriminada libertad asociativa criticada entre muchos otros por Chistopher Norris, la impronta filosófica en la teoría literaria se circunscribe a los autores cuya deuda ha sido sancionada por el canon y reconocida por sus acreedores directos. Por si fuera poco, en la mayoría de los casos, la herencia de esos autores queda acotada a los fragmentos específicamente dedicados a la estética o la filosofía del arte, que quedan así aislados de sus respectivos contextos originales. Retomando los casos señeros en que se apoya Zima, la Crítica del juicio kantiana se reduce a ciertos pasajes de la Analítica de lo bello y lo sublime y los parágrafos sobre el genio y las bellas artes, mientras la Estética de Hegel se concentra en la tercera parte, y cuando toma en consideración las dos anteriores lo hace descuidando el lugar sistemático que ocupan en la obra del autor. ${ }^{11}$ Ahora bien, incluso para el enfoque filológico más convencional resulta evidente que, así como la transmisión de elementos culturales pertenecientes a las esferas económica, política o social escapan a la asunción de una huella confesa o a la directa confrontación con las autoridades versadas en las respectivas materias, el corpus programático de la tradición poético-teórica no puede agotar la injerencia del discurso filosófico en el literario. Y si resulta obvio que la influencia filosófica sobre la creación literaria desborda por fuerza el terreno de las referencias explícitas (basta con recordar la huella de Erasmo en España según Bataillon, o la de Nietzsche según Valverde), todo invita a pensar que lo mismo ocurre con la que ejerce sobre la tradición poética. Esta mantiene con la filosofía toda una red subterránea de secretos vínculos, ecos y afinidades, de indirectas correspondencias y apropiaciones latentes, que han prolongado su alcance más allá de las referencias explicitadas por los textos programáticos. Así, junto a la autoridad de Aristóteles y Séneca, sobre las poéticas del barroco planea el neoestoicismo de Lipsio y, desde luego, la teoría política de Hobbes, pero también conexiones que remiten más allá del contexto histórico cultural inmediato que establecen un diálogo incluso con testimonios filosóficos cronológicamente posteriores, como nos enseña la estética de la recepción.

11 La continuidad de esta tendencia queda patente en una compilación tan destacada como The Norton Anthology of Theory and Criticism (Leitch, 2001), donde se recogen, entre otros, fragmentos aislados de la Crítica del Juicio sobre lo bello y lo sublime junto a los textos más relevantes de la moderna teoría literaria. 
En efecto, cuando Zima repara en que una misma línea conceptual conecta el formalismo ruso con la teoría crítica, la estética de la recepción y la deconstrucción, está constatando ya que esa transferencia se produce al margen de los documentos programáticos; y cuando Norris aduce una doble deuda de la crítica literaria moderna con Spinoza sitúa de entrada esa deuda más allá de las marcas textuales probadas. Uno y otro descubren en sus respectivos estudios la incuestionable existencia de un espacio relacional comprendido entre la estricta crítica textual sujeta a testimonios contrastados y la indiscriminada asociación del paradigma competitivo. Al presupuesto de que la concepción de la literatura adoptada por un determinado contexto histórico-cultural desborda el cauce de sus documentos poetológicos, debe añadirse pues que si escapa a lo que atestiguan esos documentos lo hace sin que ello suponga necesariamente remitir a una arbitraria libertad de vínculos casuales, esto es, sin resultar totalmente ajeno a la lógica de la transmisión histórica. Abordar siquiera parcialmente el alcance de esos vínculos soterrados constituye una tarea pendiente en el estudio de las relaciones entre filosofía y poética, limitado hasta ahora o bien a una indiscriminada libertad asociativa, o bien a una estricta obediencia de las deudas refrendadas por los testimonios poetológicos. En lo que sigue quisiera proponer una posible vía para iniciar la exploración de ese territorio intermedio.

\section{La filosofía conoce razones que la teoría ignora}

Detengámonos para empezar en un caso tan célebre como la expulsión de los poetas en la república platónica, principio y fundamento del primado ejercido por el logos sobre el mythos, el entendimiento sobre la mímesis, y la escritura sobre la oralidad, en la tradición occidental. Si en lugar de contemplar aisladamente, como es habitual, la discusión en torno a la poesía del Libro X, se la inserta en el plan general trazado por La República, la condena de la poesía y los poetas se muestra bajo una nueva luz. Teniendo en cuenta que ese plan no persigue tanto el estudio de la república en cuanto que ideal utópico como el del lugar que la moral y su enseñanza ocupan en ella, se hace patente que no es la poesía como 
tal lo que Platón convierte en blanco de su crítica, sino el ámbito de su función formativa. En efecto, si como sostiene Havelock en su clásico estudio, la disputa central de La República gira en torno a la pertinencia de dos modelos educativos contrapuestos (1994, p. 26), el rechazo de la poesía sería en realidad el de su valor como organización enciclopédica del conocimiento, como forma fidedigna de vehicular el saber transmitido. Así, una rigurosa y consecuente contextualización de la crítica platónica a la poesía se traduce ante todo en el cuestionamiento de su alcance político como instrumento formativo.

Pero al poner de relieve esta circunstancia, Havelock no está interrogando sólo el alcance tradicionalmente concedido a la crítica platónica de la poesía o, lo que es lo mismo, no se limita a poner en entredicho sus premisas desde la perspectiva histórica de la crítica textual. Su relectura repercute también en la concepción tanto de la filosofía y de la literatura como de la relación entre ambas sancionada por el canon: interpela esa tradición desde lo que constituye uno de sus documentos fundacionales, encontrando en ella nuevos acuerdos e implicaciones. Así se pone particularmente de manifiesto cuando nos centramos en la posible conciliación entre poesía y filosofía. Esa conciliación ha sido reiteradamente propuesta desde los géneros instructivos de la primera ilustración hasta la novela intelectual de un Thomas Mann o un Aldous Huxley, entendiendo siempre que entraba en abierta contradicción con la interpretación convencionalmente asumida de la poesía en Platón. La perspectiva abierta por Havelock habilita sin embargo un margen interpretativo de La República desde el cual fundamentar la posibilidad de una poesía filosófica. Así lo ha hecho en efecto buena parte de la crítica especializada (Soares, 2003; Aguirre, 2013; Waits, 2014), mostrando no solo que la reinterpretación del lugar ocupado por la poesía en el texto platónico propicia una correspondencia con la idea de poesía filosófica, sino que esa correspondencia contribuye a renovar el repertorio de la tradición poética.

En efecto, el ejemplo de la poesía en la república platónica pone de manifiesto cómo la reconstrucción del contexto originalmente ocupado por un tópico transmitido de la filosofía a la tradición poético-teórica no responde solo a un prurito de autentificación 
filológica. La interpretación del concepto artístico-literario conforme al propósito inicialmente asumido por el conjunto de la obra filosófica implica además un replanteamiento de los fundamentos constitutivos de la tradición poético-teórica, interpelados ahora desde una relectura de los textos que han conformado su noción del arte y la literatura. Conforme a la ejemplar lección hermenéutica de Peter Szondi (1992, pp. 13-42), la reconstrucción crítico-textual repercute inevitablemente en el posicionamiento teórico como sucede también a la inversa. Y es la necesaria imbricación entre ambos niveles lo que aporta un nuevo enfoque a la teoría literaria, que se apropia por un lado del potencial interpretativo proporcionado por la confrontación con un nuevo entorno discursivo sin dejar por el otro de reconocer la filiación histórica que le une a él. La teoría literaria nos enseña que la inserción de un concepto en el entramado de redes significativas comprendido por su texto de procedencia no determina en ningún caso el sentido que le confiere su apropiación por parte de los sucesivos horizontes discursivos. Aunque no podamos hablar en consecuencia de una dimensión interpretativa provista de un último e incontrovertible fundamento probatorio, sí cabe hacerlo de una particularmente productiva e iluminadora, que cuenta con la doble virtud de interpelar a una tradición poética y hacerlo desde un soporte textual que mantiene vínculos históricamente probados con esa misma tradición.

La remisión de los tópicos de la filosofía estética transmitidos por la poética a sus contextos originales supone por tanto de entrada su restitución a las implicaciones del campo significativo que los albergaba. En cuanto que nexo textual del que fueron extraídos, nos encontramos por un lado con un entorno discursivo propicio a acoger ese concepto como parte de un sistema coherente, y por el otro con un testimonio textual cuyas huellas inevitablemente se dejarán notar en el correspondiente entorno cultural. Consideradas individualmente, ambas circunstancias corresponden con los dos procedimientos hermenéuticos cuyas limitaciones han quedado sobradamente constatadas por la crítica: la inscripción en un todo significativo coherente no atento a otras consideraciones enlazaría con el uso indiscriminado de las fuentes filosóficas por parte de la teoría literaria, mientras que la transmisión por vía de préstamos 
textuales históricamente probados se supedita a la crítica filológica más ortodoxa. En cambio, la confluencia entre una y otra vía que resulta de devolver los conceptos estéticos a sus contextos filosóficos de procedencia da pie a un particular modo de aproximación crítica dotado de un singular alcance interpretativo.

La conformidad a fin sin fin kantiana, la dimensión filosófica que Schelling atribuye a la poesía, la facultad del arte y la literatura para expresar la voluntad según Schopenhauer, o para mostrar la falacia que subyace a toda representación de la verdad según Nietzsche, son algunos de los tópicos procedentes de la filosofía estética que han dejado su impronta en la poética y la teoría literaria. Común a todos es que su apropiación ignora en mayor o menor o medida las implicaciones del lugar que ocupaban en sus respectivos textos de procedencia. Nada tiene de anómala esa adulteración en la transferencia a un campo de conocimiento regido por intereses y objetivos propios: los motivos específicos que Schelling tomó en consideración para concluir la supremacía filosófica del arte en el sexto capítulo del Sistema del idealismo trascendental, o Schopenhauer para respaldar su prerrogativa metafísica en El mundo como voluntad y representación quedan diluidos en el horizonte de la tradición poético-teórica que se sirve de ellos. Lo relevante sin embargo es que la restitución de estos conceptos a sus entramados textuales de procedencia propicia un replanteamiento de los presupuestos que fundamentan su tradición poético-teórica o, lo que es lo mismo, una expansión de los recursos con que cuenta esa tradición para dar cuenta de lo que entiende por literatura.

Muestra ejemplar de ello es el principio kantiano de conformidad a fin (Zweckmäßigkeit), cuyo potencial para la teoría narrativa he puesto ya de manifiesto en otro lugar (Garrido Miñambres, 2014). Desde hace dos siglos una extendida convención atribuye a la Crítica del juicio y al concepto de conformidad a fin sin fin la noción, tan cara a la modernidad, de autonomía artística. El libre juego entre entendimiento y razón, que está en la base del juicio estético, habría alumbrado la posibilidad de un arte ajeno a las servidumbres del correspondiente entorno discursivo y sus motivaciones espurias así como, por extensión, de una literatura exclusivamente atenta a la consecución de su propósito inmanente. Un examen, ya no riguroso, 
sino mínimamente atento al tratamiento que recibe la belleza artística en la "Analítica del juicio estético" basta sin embargo para descubrir lo infundado de esta suposición. La obra de arte, en cuanto que producto de la voluntad humana (pues no de otro modo entiende el arte Kant) participa de la belleza adherente, que a diferencia de la pura presume una conformidad a fin lógica y persigue un modelo de perfección. Como no obstante el autor dotado de genio es capaz de hacer pasar la belleza artística por natural y la conformidad a fin lógica por formal, comprobamos que el arte bello obedece en Kant a un doble orden regulativo. La obra de arte reconoce por un lado una conformidad a fin real acorde a su condición de producto técnico, y por el otro una subjetiva derivada de su capacidad para parecer naturaleza sin la voluntad de hacer pasar su empeño por un engaño.

Ahora bien, si el producto artístico reclama necesariamente una conformidad a fin real y por tanto la sujeción a un determinado concepto de fin, cabría ir un paso más allá y preguntarse cuál es en particular ese concepto en el caso, por ejemplo, del género narrativo. La conformidad a fin objetiva del juicio teleológico y la subjetiva del estético tienen como fundamento común una conformidad a fin formal, entendida como el vínculo que garantiza la mera posibilidad de acuerdo entre lo particular y lo universal. Teniendo en cuenta que ese vínculo es el mismo que presume la comprensión de la naturaleza como un todo unitario por parte de la razón, surge la posibilidad de que el concepto de fin propio de la narración no sea otro que la propia conformidad a fin formal. A lo largo de su singladura histórica, la narración ha tenido siempre por propósito la recreación de un mundo desde la unidad de experiencia, esto es, la aprehensión de la esfera de las intuiciones desde su adecuación al fin último que en ellas presume una entidad intelectiva. La narración se plantearía entonces como objetivo la traslación de aquello que faculta al entendimiento para anticipar que la naturaleza responderá a su designio ordenador: el vínculo (la "secreta raíz común") entre la unidad de la experiencia conforme a leyes trascendentales y de la experiencia como sistema de conocimientos empíricos que solo la conformidad a fin formal hace posible.

Vemos así cómo la restitución del concepto artístico-poético a su contexto de procedencia no se agota en el cuestionamiento de las 
inferencias que han dado pie a su uso convencional, lo que propicia además una reformulación de las premisas manejadas por la poética, pero también por la teoría literaria. En el caso de la narración, la posibilidad de que encuentre su concepto de fin en la conformidad a fin formal proporcionaría un nuevo punto de partida a la teoría de la ficción, a la de los mundos posibles o a la poética cognitiva. Sabemos que Kant no postuló este concepto de fin para la narración como que la tradición poética posterior no llegó nunca a atribuírselo, pero ello no es óbice para que la teoría literaria saque partido del replanteamiento de un concepto poético a la luz de su contexto original. Se perfila así la posibilidad de un procedimiento intermedio entre la sujeción de las fuentes filosóficas a las marcas textuales explícitas y una indiscriminada confrontación con esas fuentes. El desbordamiento de las relaciones textuales probadas no se produciría aquí sin embargo tanteando más allá de los vínculos manifiestos con la fuente original sino, al contrario, llevando esos vínculos hasta sus últimas consecuencias. En lugar de promover la especulación en torno a referencias filosóficas ajenas a las ya acreditadas, se trataría de devolver esas referencias a sus nudos textuales de procedencia para obtener nuevas implicaciones de antiguas formulaciones teóricas. La restitución de los conceptos poéticos a sus contextos de procedencia constituye solo una opción más en la exploración de los vínculos potenciales entre filosofía y teoría literaria. Si bien exige una lectura atenta y disciplinada de los textos filosóficos que no es habitual en la teoría literaria, gratifica ese esfuerzo con una potencial reinterpretación de los conceptos sedimentados en la tradición poética $\mathbf{C}$ 


\section{Referencias}

Aguirre, J. (2013). Platón y el conflicto entre la vieja y la nueva poesía. Convivium, 23, 5-28. Recuperado de https://bit.ly/2IxFa5o

Asensi, M. (1995). Literatura y filosofía. Madrid: Síntesis.

Blanchot, M. (1992). El espacio literario. Barcelona: Paidós.

Bouchard, G. (1976). Literature et Philosophie. Études littéraires, 9(3), 436468. doi: https://doi.org/10.7202/500415ar

Cavell, S. (2002). En busca de lo ordinario. Líneas del escepticismo y romanticismo. Madrid: Cátedra.

Culler, J. (2002). La literaturidad. En M. Angenot, J. Bessière, D. Fokkema y E. Kushner, (Eds), Teoría literaria (pp. 36-50). México: Siglo XXI.

Danto, A. C. (2010). Philosophy and/as/of Literature. En G. L. Hagberg \& W. Jost (Eds.), A Companion to the Philosophy of Literature (pp. 52-67). Chichester: Wiley-Blackwell.

De Man, P. (1998). La ideología estética. Madrid: Cátedra.

Derrida, J. (1987). La escritura y la diferencia. Barcelona: Anthropos.

Duhamel, R. (1995). Literatur und Philosophie. Von Grenzfällen und gefallenen Grenzen. Zeitschrift für Literaturwissenschaft und Linguistik, 25(1), 114-122. doi: https://doi.org/10.1007/BF03396142

Eagleton, T. (2005). Después de la teoría. Barcelona: Debate.

Garrido Gallardo, M. A. (2001). Nueva introducción a la teoría de la literatura. Madrid: Síntesis.

Garrido Gallardo, M. A. (2014). Cervantes y la preceptiva literaria. Anales Cervantinos, 46, 179-202. doi: https://doi.org/10.3989/ anacervantinos.2014.011

Garrido Miñambres, G. (2010). República poética. Textos programáticos de la literatura española (SS. XVIII-XIX). Madrid: Dykinson.

Garrido Miñambres, G. (2014). Entre el organismo y el artefacto. Sobre la conformidad a fin narrativa, Endoxa, 34, 67-86. Disponible en https:// bit.ly/2JIcrjU

Havelock, E. A. (1994). Prefacio a Platón. Madrid: Visor.

Hagberg, G., \& Jost, W. (2010). A companion to the philosophy of literature. Chichester: Wiley-Blackwell.

Kitcher, P. (2013). Deaths in Venice. The Cases of Gustav von Aschenbach. New York: Columbia University Press. 
Lacoue-Labarthe, P. y Nancy, J.-L. (2012). El absoluto literario. Teoría de la literatura del romanticismo alemán. Buenos Aires: Eterna Cadencia.

Lamarque, P. (2009). The Philosophie of Literature. Carlton: Blackwell.

Leitch, Vincent B. (Ed.). (2001). The Norton anthology of theory and criticism. New York: Norton \& Company.

Norris, C. (1991). Spinoza and the origins of modern Critical Theory. Cambridge: Basil Blackwell.

Norris, C. (2007). Fiction, Philosophy and Literary Theory. Will the Real Saul Kripke Please Stand Up? London: Continuum.

Nussbaum, M. C. (2005). El conocimiento del amor. Ensayos sobre filosofía y literature. Madrid: Machado.

Nussbaum, M. C. (2010). Perceptive Equilibrium: Literary Theory and Ethycal Theory. In G. L Hagberg \& W. Jost (Eds.), A Companion to the Philosophy of Literature (pp. 241-267). Malden: Wiley Blackwell.

Orsi, R. (2007). El saber y el error. Filosofía y tragedia en Sófocles. Madrid: Plaza y Valdés.

Pardo, J. L. (2002). Más Prozac y menos Platón. Archipiélago, 50, 11-19.

Sauerland, K. (1993). Paradigmawechsel unter dem Zeichen der Philosophie. In C. König y E. Lämmert (Eds), Literaturwissenschaft und Geistesgeschichte 1910 bis 1925 (pp. 255-264). Frankfurt am Main: Fischer.

Soares, L. (2003). Esbozo de una discrepancia. Platón y la poesía tradicional. Kléos. Revista de filosofía, 7-8, 71-93.

Szondi, P. (1992). Estudios sobre Hölderlin. Con un ensayo sobre el conocimiento literario. Barcelona: Destino.

Thiebaut, C. (1995). Filosofía y literatura: de la retórica a la poética. Isegoría. Filosofía y literatura, 11, 81-107. Recuperado de https://bit.ly/2IwKxla

Till, D. (2013). Rhetorik und Poetik. In T. Amz (Ed.), Handbuch Literaturwissenschaft (Vol. 1, pp. 435-465). Stuttgart: Metzler.

Watts, S. (2014). ¿Puede hablarse de poesía filosófica en Platón? Eidos, 20, 75-94. Recuperado de https://bit.ly/2tg1Z89

Williams, B. (2011). Vergüenza y necesidad. Recuperación de algunos conceptos morales de la Grecia antigua. Madrid: La Balsa de la Medusa.

Zima, P. V. (1995). Literarische Ästhetik, Methoden und Modelle der Literaturwissenschaft. Tübingen: Fink. 